\title{
O que é a humanidade?
}

\section{CLAUDE LÉVI-STRAUSS (ENTREVISTA / TRECHOS)}

$\mathrm{P}$ OR OCASIÃO do desaparecimento de Alfred-Louis Kroeber, último sobrevivente da grande tradição dos etnólogos americanos, Claude Lévi-Strauss diz, nesta entrevista à L'Express, em 20 de outubro de 1960, o que representa essa perda para a etnologia mundial e responde às perguntas feitas por Madeleine Chapsal sobre o trabalho dos etnólogos.

L'Express-Quem foi Alfred-Louis Kroeber, que o senhor considera como o seu mestre e que acaba de falecer?

Claude Lévi-Strauss - Ele é o último dos etnólogos da América do Norte a ter conhecido índios. Peles-vermelhas não selvagens - evidentemente não há mais selvagens -, mas que o haviam sido na juventude. Kroeber nasceu em 1876, seu primeiro trabalho de campo sobre os Arapaho data de 1900. Ora, a penetração do Oeste pelos brancos americanos só começou por volta de 1850 e se completou por volta de 1880. Portanto, os velhos de 70 ou 80 anos que Kroeber pôde conhecer tinham levado, durante a maior parte de sua vida, a existência de índios selvagens... Com Kroeber, é realmente a América anterior a Cristóvão Colombo que morre completamente.

\section{L'Express - Onde viviam exatamente esses indios de Kroeber?}

$C L-S$ - Na Califórnia. Seu extermínio data provavelmente de 1880, já que eles eram cerca de 150 mil em 1850 e restaram apenas 20 mil depois de 1880 . Kroeber me disse também, há poucas semanas na Áustria - estivemos juntos no colóquio de Burgwartenstein -, que fazia apenas dois ou três anos que ele retornara pela última vez entre os Yurok, alguns dos quais subsistem em pequenos grupos de umas dez pessoas, às vezes com uma só família, ou mesmo uma única pessoa, que fala ainda a língua de origem e que se lembra dos mitos e das lendas. São pessoas que viviam da coleta e da caça, e que representam provavelmente o que há de mais arcaico na América.

\section{L'Express - Kroeber era o único a se interessar por eles?}

$C L-S$ - Não, houve outros etnólogos - embora Kroeber fosse o único a ter ligações muito fortes e pessoais com eles - e também psicanalistas. Estes se apaixonaram pelos índios da Califórnia, aliás recentemente e em parte por influência de Kroeber. Ele mesmo fez uma psicanálise didática durante três anos, por volta de 1920, eu acho, ao mesmo tempo que continuava o seu ofício.

\section{L'Express - Ele conbeceu Sigmund Freud?}

$C L-S$ - Creio que não, mas se correspondeu com ele e fez duas resenhas do livro de Freud sobre as sociedades primitivas, Totem e tabu. A primeira, em 
1920, demolindo-o completamente; a segunda, em 1939, bem mais matizada, tentando demonstrar em que medida um etnólogo, de um certo ponto de vista, podia aceitar algumas teses de Totem e tabu.

\section{L'Express - Em que os indios da Califórnia, por exemplo, podem interessar aos psicanalistas?}

$C L-S$ - Penso primeiramente no que os psicanalistas chamariam o seu "caráter anal”. De fato, eles eram colecionadores apaixonados, homens que acumulavam tesouros, os quais consistiam geralmente em grandes lâminas de obsidiana. Essas chapas, algumas com mais de um metro de comprimento ou mesmo um metro e meio, não podiam servir para nada, mas eles as consideravam objetos extremamente preciosos: eram exibidas em cerimônias por ocasião de jogos, que eu quase chamaria jogos de pôquer, pois se tratava de esmagar o adversário com a apresentação das lâminas mais importantes ou mais belas... Mas isso supunha toda uma estratégia, um "blefe". Quem exibisse de imediato a melhor lâmina que possuía corria o risco de ser exterminado... Assim, convinha conduzir o adversário a tentar sempre obter a vantagem, conservando em seu próprio poder as melhores lâminas ou "cartas".

L'Express - Além do fato de Kroeber ter sido o último vínculo com a América selvagem, o que fazia dele, a seu ver, uma personalidade excepcional?

$C L-S$ - Era um homem de uma vivacidade extraordinária, que em toda a sua vida foi não só etnógrafo de campo - ele estudou diretamente um número considerável de populações americanas -, mas também arqueólogo (fez escavações no Peru que permitiram propor algumas classificações, hoje clássicas, para as antigas culturas peruanas), historiador (sobre as populações desaparecidas no norte da América do Sul, como os Chicha), e uma parte de sua obra é de caráter filosófico (ele estudou até mesmo as variações da moda feminina no século passado!). Fez linguística, investigações sociológicas, dedicou todo um livro às relações entre os meios geográficos da América do Norte e sociedades que ali se desenvolveram...

Enfim, era um homem de uma curiosidade e de uma intensidade de espírito totalmente excepcionais.

L'Express - Mas, antes de tudo, um etnólogo.

$C L-S$ - Sim. Ele me disse várias vezes, aliás, o quanto estava surpreso de ver que os jovens etnólogos americanos de hoje escolhiam a etnologia por razões arbitrárias, como teriam podido escolher a sociologia ou a psicologia, como uma ciência social entre outras; ao passo que, para Kroeber e os homens da sua geração, a etnologia não era uma ciência no mesmo plano que as outras, para ele a antropologia era uma religião.

L'Express - Mas não seria uma religião perigosa? Ao ensinar a quem a pratica que todas as morais, todas as instituições, todas as formas de sociedade são sistemas que poderiam não existir e, em todo caso, que são renováveis ao infinito, não há o risco de o etnólogo sentir-se derrotado, tomado de vertigem? 
$C L-S$ - Penso, ao contrário, que isso lhe permite chegar à sabedoria...

\section{L'Express - Como assim?}

$C L-S$ - Bem, precisamente pelo sentimento de que nada do que ele vive é profundamente essencial. O que parece mais importante só o é realmente na medida em que nos situamos numa certa escala do tempo. Se o etnólogo aceitar, por uma ginástica que lhe é habitual, fazer uma conversão e se colocar, nem que seja por um instante, na escala dos séculos ou dos milênios - em vez de situar-se na escala das décadas -, as coisas que parecem fundamentais se mostrarão para ele sob uma luz bem diferente...

L'Express - Quem pensa que o senhor estuda os costumes dos homens, talvez no fundo se engane pouco. O que lhe interessa essencialmente não é o espirito humano? Seus reflexos? Sua constituição?

$C L-S$ - Sim. Mas a nossa contribuição ao conhecimento do espírito humano consiste em abordá-lo de uma outra maneira, por uma outra ponta ou um outro caminho, diferentes dos do psicólogo ou do historiador, por exemplo. Digamos que buscamos apreendê-lo naquilo que Sartre chama as "totalidades" ou as "totalizações"...

\section{L'Express - Qualé o seu instrumento, seu, em particular?}

CL-S - O distanciamento. Não apenas porque as sociedades que consideramos são muito distantes geograficamente, mas também porque o são pelo gênero de vida; e o deslocamento que elas exigem de nós para estudá-las nos condena a perceber apenas algumas propriedades que são essenciais a elas e ao espírito humano.

Nossa ciência, a antropologia, está condicionada pela distância, por esse afastamento que só deixa filtrar o essencial.

L'Express - O distanciamento, mas também a proximidade. Não bá momentos em que o etnólogo se acha diante de um homem e esse homem, nada mais, é seu objeto de estudo? Em que ele espera tudo de um próximo contato com ele?

$C L-S$ - Sim, mas convém distinguir bem as atitudes. Na América do Sul, por exemplo, as pessoas não sabiam muito bem o que era um etnólogo, e quando quem vivia entre elas lhes parecia um bom sujeito, quando estavam seguras de obter dele um certo número de vantagens materiais - sob a forma de presentes, alimentos, facas ou pérolas -, então a coisa ia bem...

Entre os grupos que Kroeber estudava, a situação era diferente. Como a etnologia começou por volta de 1840, eles souberam muito depressa, no conjunto do continente, o que era um etnólogo. Houve resistências que foi preciso vencer pelo tempo, pela espera, ou, ao contrário, uma cooperação muito viva: aquelas pessoas tinham consciência de que seu gênero de vida, aquilo que elas prezavam, estava condenado irremediavelmente e que a única chance de conservar essa lembrança para a posteridade era trabalhar com os etnólogos... Elas cooperavam com pleno conhecimento de causa para que tudo fosse transcrito, escrito, e para que alguns objetos, como altares portáteis particularmente pre- 
ciosos que representavam para uma tribo sua arca sagrada, fossem levados aos museus, pois sabiam que lá era o lugar onde eles seriam preservados. E, quando o último velho estava para morrer, ele levava seu tesouro ao museu, não havia outra solução.

\section{L'Express - O senhor acredita que nos dirigimos a uma unificação das socie- dades?}

$C L-S$ - Essa foi também uma questão que discutimos na Áustria com Kroeber. ${ }^{1}$ Ele parecia pensar assim, enquanto os outros membros do colóquio, não. Nós lhe opúnhamos que, na medida em que as sociedades tendessem à homogeneidade, provavelmente outros pontos de ruptura, outros pontos de clivagem apareceriam em lugares que de modo nenhum suspeitamos.

L'Express-Onde? Não tem a menor ideia? Seria entre a Bretanha e a Fran$c ̧ a . .$.

$C L-S$ - Talvez não. Mas quem sabe, por exemplo, no plano das gerações. Os problemas de delinquência juvenil sempre existiram em todas as épocas, mas hoje, talvez, na medida em que no plano de uma dada geração as diferenças tendem a se abolir no espaço, eles se manifestam de um modo bem mais marcado entre uma geração e a seguinte...

Acaba de ser feita na Inglaterra uma pesquisa muito curiosa sobre o folclore das crianças das escolas. Constatou-se que em toda a Inglaterra os tipos de jogos e os modos de falar das crianças - de cuja existência os adultos nem sequer suspeitam - eram notavelmente homogêneos... E não se sabe de modo algum como se deu a propagação.

L'Express - Então, mesmo se as sociedades primitivas desaparecerem da superfície da Terra, os etnólogos terão sempre trabalho?

CL-S - Sim, porque afinal a etnologia sempre se deu por tarefa explorar os limites daquilo que se considera num momento dado, numa época dada, como sendo os da humanidade. Sobre esse ponto há uma curiosa nota de J.-J. Rousseau - que se encontra no final do "Discurso sobre a desigualdade". Ele começa por se queixar de que só se façam estudos da natureza e não do homem, e faz um apelo a pessoas ou grupos muito ricos para que aceitem subvencionar viagens que tenham por finalidade ir estudar o homem (em suma, ele anuncia as grandes fundações dedicadas hoje à pesquisa antropológica!), e depois dá como exemplo isto: viajantes lhe contaram histórias muito curiosas a propósito de sociedades de estranhos seres vivos na África que se chamam "gorilas" e que, por ignorância, são declarados macacos, quando é perfeitamente claro que se trata de preconceitos e que, em realidade, esses seres são homens! E, se não fôssemos tão ignorantes sobre a diversidade dos seres humanos, veríamos que um gorila é um homem do mesmo modo que um outro!

Sobre esse ponto, admito que Rousseau se enganava; mas ele se enganava adotando uma atitude que é típica da atitude etnológica: colocar-se sempre mais além do que se considera ser o possível, para o homem, trazendo para o interior 
da humanidade fenômenos fronteiriços, fenômenos à margem. Trabalhamos para uma ciência que deve se manter sempre à margem do desconhecido. Nessa medida, haverá sempre uma etnologia.

\section{L'Express - Os etnólogos consideram estudar sua própria sociedade?}

$C L-S$ - Quanto maior é uma sociedade, mais ela se torna estranha a si mesma, mais ela se coloca problemas. É o caso dos americanos: eles tomaram consciência do fato de que, sendo uma vasta sociedade de duzentos milhões de habitantes - e não como nós, de 40 ou 50 milhões -, não se compreendem a si mesmos, o que até o presente não é uma atitude europeia. E, se a antropologia se desenvolveu tanto nos últimos anos, não foi para estudar os povos primitivos, foi para estudar a sociedade americana.

A originalidade do pensamento de Kroeber foi nunca ter querido isolar a antropologia. Tinha numa das mãos as ciências naturais, na outra as humanidades. Por exemplo, problemas como o da linguagem das abelhas, das sociedades animais, eram para ele problemas tão essenciais à história do mundo quanto os da civilização mediterrânea da Antiguidade.

Hoje todos tendem a se encerrar muito estreitamente na sua especialidade. Kroeber foi, na nossa época, um daqueles homens universais como havia no século XIX, por exemplo, e como quase não há mais...

L'Express - Mas não é cada vez mais difícil, hoje, dominar o conjunto da cultura? Não haveria muito do que se informar? Talvez seja isso que leve as pessoas a se recolherem prudentemente no setor que conhecem melhor..

$C L-S$ - Certamente ocupar-se de tudo pode levar a uma certa ingenuidade... Mas, de todo modo, estamos sempre expostos a dizer muitas bobagens, tão $\log$ o nos interessamos por coisas que não conhecemos diretamente. Então é preciso escolher.

L'Express - Será que a personalidade de quem exerce a sua profissão não conta bem mais do que numa outra disciplina?

$C L-S$ - Conta enormemente. O próprio Kroeber disse várias vezes que os sociólogos são homens sempre dispostos a jogar, digamos, o jogo de sua própria sociedade - estejam eles a favor ou contra, isso não importa; eles querem situarse no interior dela, para discuti-la ou melhorá-la. Ao passo que o antropólogo - segundo Kroeber - é, ao contrário, um homem que não se sente à vontade no interior de sua própria sociedade e que tenta se situar em relação a outras, como primeiro sistema de referência.

L'Express - De fato, perguntei-me às vezes se o antropólogo não ia em busca de outras sociedades porque não conseguia estabelecer comunicações satisfatórias com a sua própria. Lá, ele se acha numa situação muito diferente, não se trata mais de igualdade e, de todo modo, ele é o outro, o estrangeiro...

$C L-S$ - Sim, mas não é com os homens em geral que o antropólogo se comunica mal - caso contrário ele não seria antropólogo, fugiria de todos e se faria arqueólogo -, é com o seu grupo social. Por outro lado, todo o esforço do 
etnólogo, no trabalho de campo, é passar despercebido, fazer-se esquecer; é não ser alguém, é ser como um móvel... Não ser mais que um fantasma, se posso dizer, ao qual não se presta a menor atenção...

\section{L'Express - E ele consegue? \\ $C L-S$ - Às vezes.}

L'Express - Entre todas as sociedades primitivas que existiram, não houve algumas que foram, mais que a nossa, sociedades felizes? Que permitiam a seus membros se desenvolver harmoniosamente em todos os planos possíveis ao ser humano?

$C L-S$ - Oh! não, sinceramente acho que não! Penso que em todas as sociedades há pessoas felizes e outras infelizes - e nas sociedades primitivas há pessoas muito infelizes.

Para quem as vê de fora, essas sociedades podem dar a impressão de equilíbrio, pois não querem mudar. Essa é a diferença com a nossa. Compreenda, a questão não é saber se elas mudam ou se não mudam; na verdade elas mudam, porque de certo modo todas as sociedades mudam. A única diferença entre elas e nós é que temos consciência dessa mudança, nós a queremos, queremos utilizá-la - em nosso favor ou em nosso prejuízo -, queremos subjugar a história, como uma força que estaria à disposição da nossa sociedade; as sociedades primitivas, ao contrário, rechaçam, rejeitam, a história, fazem tudo o que podem para que não haja mudanças - e aliás não conseguem. Há guerras, epidemias, fomes... Tudo isso implica readaptações.

L’Express - E há também os etnólogos! O senhor deixa inalterada uma sociedade na qual penetrou?

$C L-S$ - Olhe, nesse ponto tenho a consciência mais ou menos tranquila!... Os danos que podemos causar, comparados àqueles causados pela civilização, são negligenciáveis!

L'Express - É sempre uma tolice falar da desigualdade das sociedades, mas ainda assim a nossa, nem que seja porque destrói as outras, não seria superior?

$C L-S$ - Ela é certamente muito superior, do ponto de vista do seu poder material, do seu volume, da sua densidade e do seu efetivo demográfico; ela é certamente muito superior pelo domínio que exerce sobre as forças naturais, não há dúvida nenhuma quanto a isso. A única questão que se pode colocar é: há sociedades absolutamente superiores e outras absolutamente inferiores, não somente em certos aspectos, mas em todos os aspectos?

\section{L'Express - Há?}

$C L-S$ - Não, creio que não. Penso que toda sociedade encontrou o essencial do que era necessário ao ser humano, caso contrário ela não existiria.

L'Express - Quais são as sociedades que o apaixonam mais, pessoalmente, como etnólogo?

$C L-S$ - O que há de mais sedutor em matéria de conhecimento, para um etnólogo, são as sociedades melanésias; não digo que são as mais simpáticas ou 
as mais agradáveis, mas são as mais extraordinárias. Primeiro por sua multiplicidade num território dado, é uma parte do mundo em que uma quantidade prodigiosa de experiências foi realizada, experiências extraordinariamente diferentes umas das outras; são sociedades em que a organização social coloca todo tipo de problemas, dos quais a Arte é provavelmente o mais surpreendente... Além disso, é provavelmente a única região do mundo em que existem ainda lugares desconhecidos.

L'Express - O senhor foi até lá?

$C L-S$ - Não.

L'Express - Espera retornar um dia, pessoalmente, ao trabalho de campo?

$C L-S$ - Não, creio que não. Sabe, se todos os etnólogos estão de acordo em dizer que não se pode ter essa profissão sem ter feito trabalho de campo, sem ter uma sólida experiência desse trabalho, a partir daí penso que os caminhos podem divergir. Há os que se sentem felizes quando estão entre os indígenas, e outros, é o meu caso, que têm o gosto de trabalhos mais teóricos, que, tendo adquirido a experiência do trabalho de campo, preferem colocar-se problemas teóricos... Enfim, creio que não gosto do trabalho de campo.

L'Express - No entanto, mudar de sociedade é algo que deve produzir um sentimento de deslocamento prodigioso, quase absoluto. O senhor não gostou disso?

$C L-S$ - Gostei, mas para chegar a isso somos obrigados a enfrentar o que mais detestamos no seio de nossa civilização: os problemas da partida, dos meios de transporte, das formalidades administrativas, a luta contra a inércia burocrática, a má vontade das pessoas; enfim, tudo o que desgasta... Em etnologia é como em todas as ciências, há pessoas que amam o laboratório, outras que preferem o giz e o quadro-negro. É o meu caso.

L'Express - Está preparando um livro neste momento?

$C L-S$ - Sim, um volumoso livro de mitologia, mas lentamente. Trata-se de uma série de experiências mitológicas, se ouso dizer... A partir de exemplos muito variados, tento mostrar que os mesmos métodos de explicação ou de interpretação podem funcionar.

L'Express - Quem são hoje os maiores etnólogos?

$C L-S$ - Na América, há o fim de uma geração. O fundador da etnologia americana foi Boas, e ele morreu em 1942; restaram os seus grandes discípulos: Lowie, Radin e Kroeber, e os três acabam de morrer nos últimos três anos. E o mais brilhante da geração imediatamente seguinte, Kluckholn, morreu neste verão aos 57 anos de idade.

L'Express - E, em outros lugares, quem citaria?

$C L-S$ - A escola inglesa é excelente: há Evans-Pritchard, Forter, Firth. Há alguns excelentes na Holanda, na Austrália...

L'Express - E na Rússia?

$C L-S$ - Os russos estão atrasados por causa da guerra. Ficaram separados 
durante muito tempo da produção etnográfica do resto do mundo. A mesma coisa na Alemanha. A Alemanha foi um dos primeiros países do mundo em etnologia até o hitlerismo, depois houve uma ruptura... Eles precisam se recuperar.

\section{L'Express - Quem foi o primeiro etnólogo?}

$C L-S$ - Não posso responder a essa pergunta. Ou então the direi que foi Heródoto, e houve outros antes dele... O que tanto fez penar nas salas de aula nossos pais e nossos avós, o latim e o grego, pois bem, isso era etnologia! O esforço que exigiam não é tão diferente do que fazemos quando estudamos índios do Brasil ou australianos. Sim, o latim e o grego tentavam ensinar a julgar sua própria cultura na perspectiva ampliada que o conhecimento de culturas diferentes produz, e no fundo é isso o que se chama de humanismo...

\section{L'Express $-E$ as humanidades?}

$C L-S$ - Creio que o papel desempenhado pelos estudos clássicos no passado não é essencialmente diferente do que poderia ter hoje a etnologia; a etnologia é simplesmente o humanismo de um outro mundo, de um mundo que se dilatou, que trouxe de volta para o interior da humanidade coisas que até então estavam fora.

Aliás, nos Estados Unidos, onde os clássicos têm um papel muito pequeno no ensino secundário, os americanos construíram um humanismo à parte, no qual a etnologia e o estudo das civilizações exóticas ocupam uma porção relativamente maior que o estudo das civilizações da Antiguidade. Na França, a dosagem é inversa: a etnologia só comparece como um arremate... Mas não há descontinuidade.

Acredito profundamente que as humanidades são a humanidade; e a humanidade são os selvagens, do mesmo modo que os sábios da Índia e da Grécia.

Nota

l A resenha desse colóquio foi publicada em inglês pela Wenner-Gren Foundation, cuja sede fica nos Estados Unidos. Seu presidente, de origem húngara, o etnólogo Paul Fejos, foi um dos mestres do cinema de vanguarda antes da guerra. Ele realizou, entre outros, o filme Solitude, bem conhecido dos aficionados das cinematecas. Sob os auspícios da Wenner-Gren Foundation, um colóquio dedicado à etnologia realiza-se todo ano, desde 1953, no castelo de Burgwartenstein, nos arredores de Viena, Áustria.

Publicado em Hors Série - La Lettre du Collège de France, Claude Lévi-Strauss - Centième anniversaire, Novembre 2008. Entrevista concedida à revista L'Express em 20 de outubro de 1960 (trechos). Tradução de Paulo Neves. O original em francês "L'humanité c'est quoi?" - encontra-se à disposição do leitor no IEA-USP para eventual consulta.

Recebido em 16.7.2009 e aceito em 21.8.2009. 